\title{
Thrombophlebitis migrans: a further systemic complication of ulcerative colitis
}

\author{
H. L. ElliotT \\ M.B., Ch.B., M.R.C.P. \\ Stobhill General Hospital, Glasgow G21 3UW
}

\begin{abstract}
Summary
Thrombophlebitis migrans complicating ulcerative colitis has been reported only once previously when it occurred in a patient with chronic and extensive bowel disease. This report describes the occurrence of thrombophlebitis before any bowel upset in a patient who proved to have only a mild colitis, and no laboratory evidence of hypercoagulability. It seems that thrombophlebitis migrans is a further systemic complication of ulcerative colitis, and that its occurrence may precede overt bowel disease.
\end{abstract}

\section{Introduction}

A variety of systemic complications occur in association with ulcerative colitis, and it is well recognized that some of these complicating lesions may precede the bowel disease.

This report concerns an association between thrombophlebitis migrans and ulcerative colitis, with the additionally unusual feature that the thrombophlebitis was the patient's reason for presentation, before any bowel symptoms.

\section{Case report}

A 37-year-old joiner, with no past history of bowel upset, was referred with a history of transient painful swellings of the left forearm (twice) and right calf. $\mathrm{He}$ had no other complaints and no alimentary symptoms. Each swelling had resolved spontaneously and completely after a few days, and examination at this time was unhelpful.

Two years previously he had experienced generalized joint pains and back stiffness, associated with a painful, raised, erythematous rash on both shins. He was told that he had erythema nodosum, and all had resolved over a period of weeks without specific treatment.

He was reviewed one month later when he felt well, but he admitted to slight, although untroublesome, looseness of his customary single daily bowel action.

He returned 6 weeks later because of recurrence of pain and swelling and was found to have signs of a venous thrombosis with tenderness, induration, and oedema of the right forearm. He also gave one week's history of diarrhoea, 2 or 3 watery stools daily, occasionally containing fresh blood, and associated with abdominal discomfort. With an initial diagnosis of thrombophlebitis migrans he was admitted for further investigation.

The diagnosis of ulcerative colitis was based on characteristic sigmoidoscopic appearances; typical rectal biopsy histology; and barium enema features of a mild colitis involving sigmoid and descending colon.

Other investigations included: ESR, $50 \mathrm{~mm} / 1 \mathrm{st} \mathrm{hr}$ (Westergren); $\mathrm{Hb}, 12.0 \mathrm{~g} / \mathrm{dl}$ with normal indices, leucocyte count normal with no eosinophilia; platelet count, complement levels, fibrin degradation products, fibrinogen, factor VIII, plasminogen and antithrombin III were all normal; slight prolongations of prothrombin time to $19 \mathrm{sec}$ (control $13 \mathrm{sec}$ ) and of partial thromboplastin time to $64 \mathrm{sec}$ (control, $40 \mathrm{sec}$ ); serum iron $5 \mu \mathrm{mol} / 1$, total iron-binding capacity $78 \mu \mathrm{mol} / \mathrm{l}$, and saturation $6 \%$; albumin $40 \mathrm{~g} / 1$; alkaline phosphatase 251 i.u./l (normal range, 40-115 i.u./l), alanine transaminase 99 i.u./l (normal range 11-55 i.u./l), aspartate transaminase 69 i.u./l (normal range 13-42 i.u./l). HLA tissue type A1.A2.B8.B12. Pelvic radiology showed slight sclerosis of the left sacro-iliac joint.

\section{Discussion}

This patient presenting with migratory thrombophlebitis was found to have ulcerative colitis, and a past history of erythema nodosum and possible ankylosing spondylitis.

Migratory thrombophlebitis is an uncommon but well recognized complication of malignant disease, classically of pancreas. This has been attributed to the release of a thromboplastic substance from degenerating tumour cells (Soong and Miller, 1970), or alternatively to some tumour-induced immunological disturbance. Either mechanism might operate in ulcerative colitis, where the cell turnover rate is increased, and indeed other cutaneous complications 
of ulcerative colitis are thought to be manifestations of immunological disturbance. The sole previous report of this association (Camilleri and Fenech, 1977) describes a patient with severe and extensive ulcerative colitis of 13 years' duration. There would be some suspicion of an underlying malignant or premalignant state in such a patient, and although it is not possible with absolute certainty to exclude an underlying neoplasm in this case, the patient is now completely well on maintenance oral sulphasalazine with no bowel upset, no biochemical or haematological abnormality, and an ESR of $2 \mathrm{~mm} / \mathrm{hr}$.

Thromboses in the leg and pelvic veins are well known to occur in ulcerative colitis, but typically in young women with fairly severe colitis and the associated non-specific predisposing factors of dehydration, anaemia, bed rest, etc. This patient was at work until his admission; the thromboses mainly involved his arms; and he had only iron deficiency and slightly deranged liver function to complicate his relatively mild colitis.

The high incidence of complicating thromboembolic disease has been more specifically ascribed to a state of hypercoagulability which occurs in ulcerative colitis, and relates to disease and activity. This hypercoagulability seems to be due to acceleration of the early stages of coagulation (Lee et al., 1968) but coagulation studies failed to confirm such a tendency in this patient.

It is also noteworthy that this patient developed erythema nodosum before any overt bowel disease (a rare occurrence in itself) and both this and the thrombophlebitis may be different manifestations of an immunological disturbance which may noB necessarily have a close temporal relationship tódisease activity in the bowel. Recent work (Gould $\overrightarrow{\overrightarrow{\vec{F}}}$ Brash and Conolly, 1977) has implicated increased? synthesis of prostaglandins in the aetiology of ulcerative colitis and it is attractive to postulate tha this is the important common factor in a systemic disease which primarily affects the colon, but which? has other inflammatory and thrombotic maniw festations.

It is concluded that thrombophlebitis migrans is $\mathrm{a}-$ further systemic complication of ulcerative colitis $\vec{\omega}$ and that its occurrence may precede the bowefo symptoms.

\section{Acknowledgment}

I thank Dr A. I. Macdougall for permission to report this case.

\section{References}

Camilleri, M. \& Fenech, F.F. (1977) Thrombophlebitis migrans in ulcerative colitis. Postgraduate Medical Journal $\bar{Z}$ 53, 762.

Gould, S.R., Brash, A.R. \& Conolly, M.E. (1977) In creased prostaglandin production in ulcerative colitis. Lancet, ii, 98.

Lee, J.C.L., SpitTell, J.A., SAuer, W.G., OWen, C.A.0 THOMPSON, J.H. (1968) Hypercoagulability associated wh chronic ulcerative colitis: changes in blood coagulatin factors. Gastroenterology, 54, 76.

SOONG, B.C.F. \& MiLleR, S.P. (1970) Coagulation disorders in cancer-III: Fibrinolysis and inhibitors. Cancer, 25 (2) 867. 